\title{
Synthesis and evaluation of an oil-soluble viscosity reducer for heavy oil
}

\author{
Guo Jixiang ${ }^{1 *}$, Wang Heyi' ${ }^{2}$, Chen Chaogang ${ }^{3}$, Chen Yun ${ }^{4}$ and Xie Xiaohai ${ }^{5}$
}

\author{
${ }^{1}$ Enhanced Oil Recovery Research Center, China University of Petroleum, Beijing 102249, China \\ ${ }^{2}$ Research Institute of Shaanxi Yanchang Petroleum(group) Co. Ltd, Shaanxi 710075, China \\ ${ }^{3}$ Northwest Oilfield Branch Engineering and Technology Institute of Sinopec, Urumchi 830011, China \\ ${ }^{4}$ Tuha Oilfield, Hami, Xinjiang 839009, China \\ ${ }^{5}$ Yumen Oilfield Yaerxia Operation Area, Gansu 735019, China
}

(C) China University of Petroleum (Beijing) and Springer-Verlag Berlin Heidelberg 2010

\begin{abstract}
To reduce the viscosity of highly-viscous oil of the Tahe oilfield (Xinjiang, China), an oilsoluble polybasic copolymer viscosity reducer for heavy oil was synthesized using the orthogonal method. The optimum reaction conditions are obtained as follows: under the protection of nitrogen, a reaction time of $9 \mathrm{~h}$, monomer mole ratio of reaction materials of 3:2:2 (The monomers are 2-propenoic acid, docosyl ester, maleic anhydride and styrene, respectively), initiator amount of $0.8 \%$ (mass percent of the sum of all the monomers) and reaction temperature of $80^{\circ} \mathrm{C}$. This synthesized viscosity reducer is more effective than commercial viscosity reducers. The rate of viscosity reduction reached $95.5 \%$ at $50{ }^{\circ} \mathrm{C}$. Infrared spectra (IR) and interfacial tensions of heavy oil with and without viscosity reducer were investigated to understand the viscosity reduction mechanism. When viscosity reducer is added, the molecules of the viscosity reducer are inserted amongst the molecules of crude oil, altering the original intermolecular structure of crude oil and weakening its ability to form hydrogen bonds with hydroxyl or carboxyl groups, so the viscosity of crude oil is reduced. Field tests of the newly developed oil-soluble viscosity reducer was carried out in the Tahe Oilfield, and the results showed that $44.5 \%$ less light oil was needed to dilute the heavy oil to achieve the needed viscosity.
\end{abstract}

Key words: Oil-soluble, viscosity reducer, heavy oil, synthesis, evaluation

\section{Introduction}

Heavy oil makes up a fairly large proportion of oil resources around the world. Reserves of heavy oil, extraheavy oil and natural asphalt all over the world are about $100 \times 10^{9} \mathrm{t}$ (Lv et al, 2005; Dai et al, 2004). With the depletion of light oil reserves and the improvement of oil production technology, the proportion of the heavy oil recovery will increase in the 21st century (Sun and zhang, 2005; Liu et al, 2005). The heavy oil recovery technology in China has been developing rapidly since 1960 s. Up to now, technologies for heavy oil thermal recovery including steam stimulation and steam drive methods, and technologies for heavy oil cold production including alkaline drive, polymer drive and miscible flooding, have been developed and widely used (Fan et al, 2007; Zhou et at, 2007). Most of the technologies have been widely applied in heavy oil development and achieved good results. Because of the high viscosity, high density and poor fluidity of heavy oil, reducing viscosity has become the key in heavy oil exploitation, transportation and

*Corresponding author. email: guojx002@163.com

Received April 8, 2010 refining. At present, the main ways to reduce the viscosity of heavy oil are thermal recovery (by means of heating cables, electric heating oil-pumping rod, and heat-conducting oil ), dilution method by using light oil, viscosity reduction by emulsification and so on. Among these methods, the thermal recovery is relatively mature and has better effect, but because of its high electricity consumption the cost is high (Chang and Zhang, 2006; Chen et al, 2004). The thin oil dilution method has no effect on the post-treatment of recovered fluid, however, it can cause a waste of thin oil and its production cost is high (Zhang et al, 2006). The density of Tahe crude oil is between $0.9950 \mathrm{~g} / \mathrm{cm}^{3}$ and $1.099 \mathrm{~g} / \mathrm{cm}^{3}$, with an average value of $1.0094 \mathrm{~g} / \mathrm{cm}^{3}$. The kinematic viscosity $(50$ ${ }^{\circ} \mathrm{C}$ ) of Tahe crude oil is between $48,170 \mathrm{mPa} \cdot \mathrm{s}$ and $1,800,000$ $\mathrm{mPa} \cdot \mathrm{s}$, and the freezing point is between $8{ }^{\circ} \mathrm{C}$ and $60^{\circ} \mathrm{C}$, with an average value of $33{ }^{\circ} \mathrm{C}$. So the crude oil of Tahe oilfield is heavy oil. The oil-soluble viscosity reducer can be added directly, avoiding post-processing problems which occur in viscosity reduction by emulsification. However, the rate of viscosity reduction of heavy oil by the existing commercial oil-soluble viscosity reducers is not satisfactory, and the study of oil-soluble viscosity reducers is rarely reported abroad and in China work has progressed slowly (Wu and Guo, 2003). 
In addition, the oil-soluble viscosity reducer can work well only when it interacts well enough with colloid and asphalt molecules of heavy oil, and the conditions at the bottom of the wells have great effect on its application. Up to now, we have not found reports of heavy oil recovery by viscosity reduction with only oil-soluble viscosity reducer (Zhang, 2006; Wang, 2006). So it was urgent to develop a suitable oilsoluble viscosity reducer for Tahe heavy oil. In this paper, an oil-soluble viscosity reducer was synthesized and its properties evaluated, and it was found that the synthesized oilsoluble viscosity reducer is more efficient than commercial ones. Field testing of the new developed oil-soluble viscosity reducer was carried out in the Tahe Oilfield of Xinjiang.

\section{Experimental}

\subsection{Reagents and instruments}

TK1074 and TK1232 crude oil were from the Tahe oilfield (Xinjiang, China), and formation water was from the $21 / 5$ well station of Tahe oilfield; Methyl stearate, ethyl stearate and vinyl acetate were all analytically pure. Kerosene (with an interfacial tension of $46.61 \mathrm{mN} \cdot \mathrm{m}^{-1}$ ) was treated by silica gel, and pentane, benzene, ethanol, petroleum ether (90-120 ${ }^{\circ} \mathrm{C}$ ) were all analytically pure.

TK1074 Tahe model oil was made by using the kerosene as solvent and TK1074 Tahe crude oil as solute with a mass fraction of $10 \%$.

Instruments: MAGNA-IR 560 Infrared spectrometer (Nicolet Co., USA), Dataphysics DCAT-21 interfacial tensiometer (Dataphysics Co., Germany), SVR·S interfacial viscoelastic meter (Kyowa Kagaku Co. Ltd., Japan), and Haake RV2 viscometer (HAAKE Co., Germany).

\subsection{Synthesis of oil-soluble viscosity reducer}

Using the four factors and three levels orthogonal test method (see Table 1), the monomer ratio, initiator amount, reaction temperature and reaction time were all optimized and oil-soluble viscosity reducers (terpolymer, quadripolymer 1, quadripolymer 2 and quadripolymer 3 ) were synthesized under the optimum conditions. In this section, the quadripolymer's monomers are 2-propenoic acid, docosyl ester, maleic anhydride,styrene and acrylamide, respectively, while the terpolymer's monomers are 2-propenoic acid, docosyl ester, maleic anhydri de and styrene. The initiator is ADMVN and the solvent is methylbenzene.

\subsection{Determination of interfacial tension}

The influence of different concentrations of oil-soluble viscosity reducer on the interfacial tension between TK1074 Tahe model oil (with a mass fraction of $10 \%$ ) and formation water was determined at $25{ }^{\circ} \mathrm{C}$ with Dataphysics DCAT-21 interfacial tensiometer.

\subsection{Determination of interfacial shear viscosity}

The interfacial shear viscosity of TK1232 crude oil in formation water was measured with SVR-S interface viscoelastic meter.
Table 1 Orthogonal test table

\begin{tabular}{ccccc}
\hline \multirow{2}{*}{ Levels } & \multicolumn{4}{c}{ Factors } \\
\cline { 2 - 5 } & $\begin{array}{c}\text { Monomer } \\
\text { ratio }\end{array}$ & $\begin{array}{c}\text { Temperature } \\
{ }^{\circ} \mathrm{C}\end{array}$ & $\begin{array}{c}\text { Initiator } \\
\text { dosage, wt } \%\end{array}$ & $\begin{array}{c}\text { Reaction time } \\
\mathrm{h}\end{array}$ \\
\hline Level 1 & $3: 1: 1$ & 70 & 0.6 & 8 \\
Level 2 & $3: 2: 1$ & 80 & 0.8 & 9 \\
Level 3 & $3: 2: 2$ & 90 & 1.0 & 10 \\
\hline
\end{tabular}

\subsection{Evaluation of oil-soluble viscosity reducer}

The viscosity of heavy oil from Tahe oilfield was measured according to China petroleum industry standard SY/T 5767-2005 "Technical specification for practice of transporting crude oil treated with pour point depressants through pipeline" and SY/T 0520-2008 "Viscosity determination of crude petroleum-Equilibrium method by rotational viscometer". The measurement is carried out at 50$90{ }^{\circ} \mathrm{C}$. The rate of viscosity reduction is calculated as follows:

$$
\varepsilon_{\mu} \%=\frac{\mu_{1}-\mu_{2}}{\mu_{1}} \times 100
$$

where $\varepsilon_{\mu} \%$ is the rate of viscosity reduction; $\mu_{1}$ is the apparent viscosity of crude oil, $\mathrm{mPa} \cdot \mathrm{s} ; \mu_{2}$ is the apparent viscosity of viscosity-reduced crude oil, $\mathrm{mPa} \cdot \mathrm{s}$.

\section{Results and discussion}

\subsection{Results of orthogonal tests}

Oil-soluble viscosity reducers were synthesized under different reaction conditions shown in Table 1 . The rate of viscosity reduction of TK1232 crude oil was studied at different conditions ( $w$ (mass of light oil): $w$ (mass of heavy oil $)=0.4: 1$, and the amount of viscosity reducer was $1 \%$ of the total mass of thin and heavy oils) to get the optimum reaction conditions. The results are shown in Table 2. The initiator amount is the percentage of the the total mass of monomers (except solvent).

Table 2 Orthogonal test results

\begin{tabular}{cccccc}
\hline Project & $\begin{array}{c}\text { Monomer } \\
\text { ratio }\end{array}$ & $\begin{array}{c}\text { Temperature } \\
(T),{ }^{\circ} \mathrm{C}\end{array}$ & $\begin{array}{c}\text { Initiator } \\
\mathrm{wt} \%\end{array}$ & $\begin{array}{r}\text { Time }(t) \\
\mathrm{h}\end{array}$ & $\begin{array}{c}\text { Rate of viscosity } \\
\text { reduction at } 50{ }^{\circ} \mathrm{C} \\
\%\end{array}$ \\
\hline 1 & $3: 1: 1$ & 70 & 0.6 & 8 & 56.7 \\
2 & $3: 1: 1$ & 80 & 0.8 & 9 & 72.0 \\
3 & $3: 1: 1$ & 90 & 1.0 & 10 & 57.3 \\
4 & $3: 2: 1$ & 70 & 1.0 & 10 & 73.3 \\
5 & $3: 2: 1$ & 80 & 0.8 & 8 & 74.7 \\
6 & $3: 2: 1$ & 90 & 0.6 & 9 & 65.3 \\
7 & $3: 2: 2$ & 70 & 1.0 & 9 & 78.7 \\
8 & $3: 2: 2$ & 80 & 0.6 & 10 & 73.3 \\
9 & $3: 2: 2$ & 90 & 0.8 & 8 & 76.0 \\
\hline
\end{tabular}


According to the above Table, analyzing the experimental results. In Table $3, K_{1}, K_{2}, K_{3}$ respectively stand for the sum of corresponding rate of viscosity reduction of the four factors and three levels of experiments; $k_{1}, k_{2}, k_{3}$ is the average value of $K_{1}, K_{2}$ and $K_{3}$, respectively.

Table 3 Analysis of orthogonal test results

\begin{tabular}{ccccc}
\hline Project & $\begin{array}{c}\text { Monomer } \\
\text { ratio }\end{array}$ & $\begin{array}{c}\text { Temperature } \\
(T),{ }^{\circ} \mathrm{C}\end{array}$ & $\begin{array}{c}\text { Initiator } \\
\mathrm{wt} \%\end{array}$ & $\begin{array}{c}\text { Time }(t) \\
\mathrm{h}\end{array}$ \\
\hline$K_{1}$ & 186.00 & 208.7 & 195.3 & 207.3 \\
$K_{2}$ & 213.3 & 220.0 & 221.3 & 216.0 \\
$K_{3}$ & 228.0 & 198.7 & 210.7 & 203.9 \\
\hline$k_{1}$ & 62.0 & 69.6 & 65.1 & 69.1 \\
$k_{2}$ & 71.1 & 73.3 & 73.8 & 72.0 \\
$k_{3}$ & 76.0 & 66.2 & 70.2 & 67.9 \\
\hline Range of $k$ & 14.0 & 7.1 & 8.7 & 3.9 \\
\hline
\end{tabular}

Table 3 shows that the influence of each factor on the rate of viscosity reduction in view of the range is in the order of monomer ratio>amount of initiator>reaction time $>$ reaction temperature. The optimum conditions for synthesizing the viscosity reducer are as follows: molar ratio of monomers of $n$ (2-propenoic acid, docosyl ester): $n$ (maleic anhydride $): n($ styrene $)=3: 2: 2$, the reaction temperature of $80{ }^{\circ} \mathrm{C}$, the amount of initiator ADMVN of $0.8 \mathrm{wt} \%$ and the reaction time of 9 hours.

\subsection{Influence of solvent amount on viscosity reducer}

According to the optimum reaction conditions obtained from orthogonal experiments, we fixed the monomers ratio, and changed the proportion of monomer and solvent (methylbenzene) to obtain $w$ (light oil): $w$ (heavy oil) $=0.4: 1$ and the amount of viscosity reducer of $2 \%$ in the total mass of thin and heavy oil. The effects of solvent on viscosity reducer at different temperatures on TK1232 were investigated and the results can be seen in Table 4 .

Table 4 Effect of solvent amount on viscosity of Tahe TK1232 crude oil

\begin{tabular}{cccc}
\hline $\begin{array}{c}\text { Mass ratio of } \\
\text { monomer to } \\
\text { solvent }\end{array}$ & $\begin{array}{c}\text { Rate of viscosity } \\
\text { reduction at } 130 \\
{ }^{\circ} \mathrm{C}, \%\end{array}$ & $\begin{array}{c}\text { Rate of } \\
\text { viscosity } \\
\text { reduction at } 90 \\
{ }^{\circ} \mathrm{C}, \%\end{array}$ & $\begin{array}{c}\text { Rate of } \\
\text { viscosity } \\
\text { reduction at } 50 \\
{ }^{\circ} \mathrm{C}, \%\end{array}$ \\
\hline $1: 1$ & 50.0 & 71.3 & 76.6 \\
$1: 2$ & 62.5 & 90.3 & 95.5 \\
$1: 4$ & 68.7 & 90.3 & 94.0 \\
\hline
\end{tabular}

Table 4 shows that the weight ratio of monomer to solvent of oil-soluble viscosity reducer has a great effect on viscosity reduction of heavy oil. In the experiment range, when the weight ratio of monomer to solvent was $1: 2$, the oil-soluble viscosity reducer had the best viscosity reducing result.

\subsection{Evaluation of oil-soluble viscosity reducer}

Under the same conditions, the viscosity reducing effects of the synthesized terpolymer and, quadripolymer viscosity reducers and commercial terpolymer on TK1232 crude oil was investigated at $90{ }^{\circ} \mathrm{C}$ and $50{ }^{\circ} \mathrm{C}$, and the results are shown in Table 5 . The viscosity of TK1232 crude oil without viscosity reducer at $90{ }^{\circ} \mathrm{C}$ and $50{ }^{\circ} \mathrm{C}$ is $1,416 \mathrm{mPa} \cdot \mathrm{s}$ and $12,881 \mathrm{mPa} \cdot \mathrm{s}$, respectively.

Table 5 The viscosity reducing effects of different copolymers on TK1232 crude oil

\begin{tabular}{|c|c|c|c|c|}
\hline \multirow[b]{2}{*}{ Viscosity reducer } & \multicolumn{2}{|r|}{$90^{\circ} \mathrm{C}$} & \multicolumn{2}{|c|}{$50^{\circ} \mathrm{C}$} \\
\hline & $\begin{array}{c}\text { Viscosity } \\
\mathrm{mPa} \cdot \mathrm{s}\end{array}$ & $\begin{array}{c}\text { Rate of viscosity } \\
\text { reduction, } \%\end{array}$ & $\begin{array}{c}\text { Viscosity } \\
\mathrm{mPa} \cdot \mathrm{s}\end{array}$ & $\begin{array}{c}\text { Rate of viscosity } \\
\text { reduction, } \%\end{array}$ \\
\hline $\begin{array}{l}\text { Commercial } \\
\text { terpolymer } 1\end{array}$ & 249 & 82.4 & 1511 & 88.3 \\
\hline $\begin{array}{c}\text { Commercial } \\
\text { quadripolymer } 2\end{array}$ & 429 & 69.7 & 3721 & 71.1 \\
\hline $\begin{array}{l}\text { Synthesized } \\
\text { terpolymer }\end{array}$ & 137 & 90.3 & 585 & 95.5 \\
\hline $\begin{array}{c}\text { Synthesized } \\
\text { quadripolymer } 1\end{array}$ & 274 & 80.6 & 1319 & 89.2 \\
\hline $\begin{array}{c}\text { Synthesized } \\
\text { quadripolymer } 2\end{array}$ & 515 & 63.6 & 1717 & 86.7 \\
\hline $\begin{array}{c}\text { Synthesized } \\
\text { quadripolymer } 3\end{array}$ & 283 & 80.0 & 4293 & 66.7 \\
\hline $\begin{array}{c}\text { Synthesized } \\
\text { quadripolymer } 4\end{array}$ & 549 & 61.2 & 6354 & 50.7 \\
\hline
\end{tabular}

Table 5 shows that the synthesized terpolymer viscosity reducer is better than commercial viscosity reducers and the quadripolymer viscosity reducers. At $50{ }^{\circ} \mathrm{C}$, the viscosity of TK1232 crude oil fell from $12,881 \mathrm{mPa} \cdot \mathrm{s}$ to $585 \mathrm{mPa} \cdot \mathrm{s}$, and the rate of viscosity reduction is $95.5 \%$, after adding the synthesized terpolymer viscosity reducer.

\subsection{IR spectra of TK1074 heavy oil with and without viscosity reducer}

IR spectra of TK1074 heavy oil with and without viscosity reducer are shown in Fig. 1. It can be seen that the intensity of the absorption peak of the hydroxyl $\mathrm{O}-\mathrm{H}$ decreased at $3,500 \mathrm{~cm}^{-1}$ after using viscosity reducer. The peak of carbonyl $\mathrm{C}=\mathrm{O}$ appeared at $1,736 \mathrm{~cm}^{-1}$ after using viscosity reducer. The structure of TK1074 crude oil had changed after using viscosity reducer.

\subsection{Influence of oil-soluble viscosity reducer on oil- water interfacial tension}

Viscosity reducer was added to $10 \%$ TK1074 Tahe model oil (the amount of viscosity reducer being $1 \mathrm{wt} \%$ of the model oil) and stirred to make the oil phase, and formation water was used as aqueous phase, to study the oil-water interfacial 


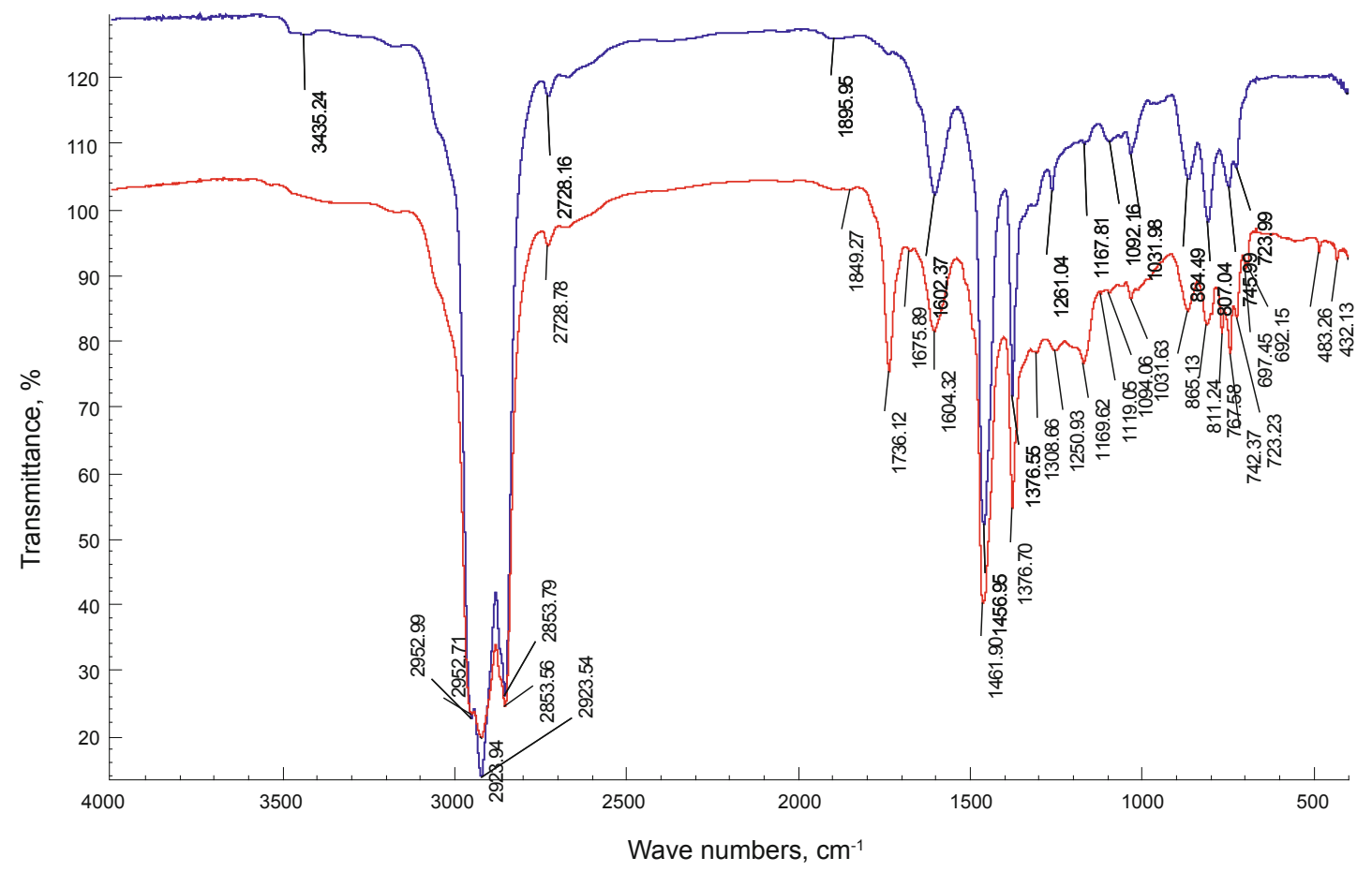

Fig. 1 IR of TK1074 crude oil with or without viscosity reducer (Blue: IR of TK1974 heavy oil, red: IR of TK1074 heavy oil with viscosity reducer)

tension with and without viscosity reducer(see Fig. 2).

Fig. 2 shows that the interfacial tension between crude model oil and formation water system decreased dramatically when using the viscosity reducer, indicating that the viscosity reducer has a high interfacial activity. The viscosity reducer can spread from the oil phase to the oil-water interface replacing macromolecular active substances from the crude oil, so a new interfacial film is formed and the interfacial tension is greatly reduced.

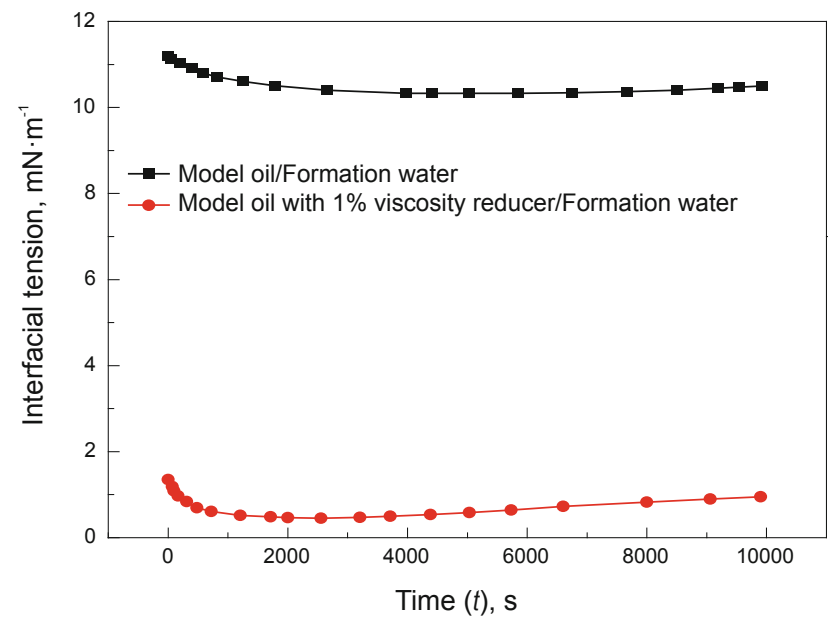

Fig. 2 Effect of viscosity reducer on interfacial tension between TK1074 crude model oil and formation water

\subsection{Field test of the oil-soluble viscosity reducer}

The field test of the developed oil-soluble viscosity reducer was carried out for two months in well TH12510 (machine pumping well) and TH12210 (flowing well) of the second oil production plant of the Tahe oilfield. Results are as follows: (1) For well TH12510, during the test, the light oil dilution ratio was reduced from 0.83 to 0.49 . In normal production conditions, the light oil needed for heavy oil dilution was decreased by $44.5 \%$, after using oil-soluble viscosity reducer, with an average saving rate of $21.0 \%$, and a maximum $6.1 \mathrm{t} / \mathrm{d}$ of light oil was saved per day, with an average saving amount of 4.5 t/d. (2) For well TH12210, during the test, the light oil dilution ratio was reduced from 1.42 to 0.99 after using oil-soluble viscosity reducer. In normal production conditions, the light oil used for heavy oil dilution was decreased by $30.4 \%$, and a maximum $12.3 \mathrm{t} / \mathrm{d}$ of light oil was saved per day, with an average saving amount of $9.0 \mathrm{t} / \mathrm{d}$.

\section{Conclusions}

1) The synthetic conditions of oil-soluble viscosity reducer are as follows: under the protection of nitrogen, reaction $9 \mathrm{~h}$, mole ratio of raw material monomer $3: 2: 2$, amount of initiator is $0.8 \%$, reaction temperature is $80{ }^{\circ} \mathrm{C}$. In the scope of $w$ (monomer): $w$ (solvent $)=1: 1 \sim 1: 4$, when $w($ monomer $): w($ solvent $)=1: 2$, there is the best viscosity reducing effect.

2) The synthetic terpolymer viscosity reducer is better than the commercial viscosity reducers and the synthesized quadripolymers. At $50{ }^{\circ} \mathrm{C}$, viscosity reduction rate is $95.5 \%$.

3) When viscosity reducer is added, molecules of viscosity reducer interact with the molecules of heavy oil altering the original intermolecular structure of heavy oil, weakening its ability to form hydrogen bonds with hydroxyl or carboxyl groups, and hence the viscosity of the crude oil is reduced. 
4) The results of field test showed that the relative savings rate of light oil was up to $44.5 \%$ after adding viscosity reducer, achieving good results.

\section{References}

Chang Y X and Zhang X J. Viscosity reduction mechanism of of oilsoluble viscosity reducer for Heavy oil. Oil-Gasfield Surface Engineering. 2006. 25(4): 8-9 (in Chinese)

Chen Q F, Wang D X and Liu R. Progress of oil-soluble heavy oil viscosity reducer. Oil Drilling and Production Technology. 2004. 26(2): 45-51 (in Chinese)

Dai S G, Cui B, Qi Y L, et al. The technology and overseas of highviscosity heavy oil recovery. Chemical Technology Economy. 2004. 22(11): 22 (in Chinese)

Fan X J, Wang X, Chen Y X, et al. Research Advances in heavy oil viscosity reduction of chemical. Chemical Industry Times. 2007. 21(3): 47-48 (in Chinese)

Liu X L. Difficult to use reserves of heavy oil recovery technology. Beijing: Petroleum Industry Press. 2005 (in Chinese)
Lv L H, Li M H and Su Y L. Overview of minng methods of heavy oil. Inner Mongolia Petrochemical Industry. 2005. (3): 110 (in Chinese)

Sun H and Zhang F S. Progress in heavy chemical viscosity reducer. Fine and Specialty Chemicals. 2005. 13(23): 16-18 (in Chinese)

Wang W Q. The Research and Application of Salt and Temperature Resistant Viscosity Reducer for Heavy Oil. Beijing: China University of Petroleum. 2006 (in Chinese)

Wu B F and Guo J B. The research progress overview of heavy oil oilsoluble viscosity reducer. Oil \& Gas Storage and Transportation. 2003. 22(2): 1-8 (in Chinese)

Zhang F Y, Li J B, Zhu L, et al. Progress of oil-soluble viscosity reducer of heavy oil. Special Oil \& Gas Reservoirs. 2006. 13(20): 1-5 (in Chinese)

Zhang F Y. Development and Evaluation of Oil-soluble Viscosity Reducer for Heavy Oil. Sichuan: Southwest Petroleum University. 2006 (in Chinese)

Zhou C, Wu C J, Ren S S, et al. Overview of heavy oil viscosity reduction method. Inner Mongolia Petrochemical Industry. 2007. (4): 128-129 (in Chinese)

(Edited by Zhu Xiuqin) 